\title{
EFFECT OF ALOE VERA GEL COATING ON THE QUALITY OF BANANA FRUIT DURING STORAGE
}

\author{
Le Pham Tan QUOC ${ }^{1}$
}

\begin{abstract}
The major goal of this study was to investigate the effect of Aloe vera gel coating on the changes in the quality of bananas at room temperature $\left(26-30^{\circ} \mathrm{C}\right)$. To evaluate the influence of different concentrations of gel, a set of experiments was designed that included solutions of Aloe vera gel diluted 1:2, 1:3, and 1:4 (v/v) with distilled water and uncoated bananas as controls. Changes in physicochemical properties were analyzed during the preservation time such as weight loss, reducing sugar, total soluble solids, acidity, sensory testing, and color parameters $\left(L^{*}, a^{*}, b^{*}\right)$. Microbiological analysis was evaluated in the last storage period. In general, bananas treated with Aloe vera gel can reduce the weight loss and improve the fruit color and sensory value of the product.
\end{abstract}

Key words: Aloe vera, banana, edible film, storage.

\section{Introduction}

Bananas belong to the genus Musa, and the family Musaceae and originates from Indomalaya and Australia, Papua New Guinea. Until now, it is cultivated widely around the world. The nutrition of this fruit is quite high, including many healthy chemical constituents, such as carbohydrates, dietary fibers, vitamins, minerals, and other bioactive compounds [20]. In Vietnam, there are many banana species that have spread to all provinces, especially Pisang Awak (Musa acuminata $\times$ Musa balbisiana). It is used as fresh fruit of processed fruits products, for instance, jam, candy, cake, juice, etc. However, the preservation time of this fruit is quite short (approximately 3 or 4 days depending on storage conditions), and its quality is not uniform. This causes difficulty in the production process.

Nowadays, the edible coating is a good solution to preserve fruits and

\footnotetext{
${ }^{1}$ Institute of Biotechnology and Food Technology, Industrial University of Ho Chi Minh City, Ho Chi Minh City, Vietnam;

Correspondence: Le Pham Tan Quoc; email: lephamtanquoc@iuh.edu.vn.
} 
environmentally friendly to nature. Using edible film can reduce the respiration rate of the fruit and improve food appearance and quality $[16,17]$. The materials of edible coating usually originate from both animal and vegetable agricultural products [17], especially Aloe vera gel. Many previous studies evaluated the advantage of this gel. For instance, according to Hassanpour [7], the author demonstrated that it maintained antioxidant capacity, total phenol, total anthocyanin, and antioxidant enzymes during storage periods of raspberry fruits. Benítez et al. [2] reported that Aloe vera coating also maintained the firmness and prevented the ascorbic acid losses and yellowing because of ripening of kiwifruit slices. In fact, Aloe vera is also a popular edible plant in Vietnam, and the chemical composition of leaf consists of $99.5 \%$ water and $0.5 \%$ of solid material [3]. It is used widely in the cosmetic industry and in juice and yogurt technology in Vietnam.

Based on the reasons mentioned above, banana storage using Aloe vera gel as the edible film is a new approach. Until now, no studies have mentioned this concept. Hence, the goal of this study was to assess the influence of Aloe vera gel on the quality and properties of bananas during storage at room temperature $\left(26-30^{\circ} \mathrm{C}\right)$ and to get a better understanding of the influence of Aloe vera on the shelf life of bananas.

\section{Materials and Methods}

\subsection{Sample Preparation}

Pisang Awak banana fruits were cultivated in Hau Giang province (Vietnam), harvested from January to March (2021), and transported at room temperature $\left(29-31^{\circ} \mathrm{C}\right)$ to the laboratory within 1 day of harvest. To ensure an even maturity of the fruit, all fruits were uniformly green with traces of yellow in color (color-stage 2), hard [24], and only undamaged hands with three fingers were chosen. The fingers were uniform in size (a length of $95.6 \pm 1.6 \mathrm{~mm}$ and a diameter of $36.2 \pm 1.2 \mathrm{~mm}$ ). A total of 36 fingers for one test were split into four groups and with Aloe vera gel. Three groups were dipped in a solution of Aloe vera gel diluted 1:2 (gel A), 1:3 (gel B), and 1:4 (gel C) with distilled water $(\mathrm{v} / \mathrm{v})$ for $30 \mathrm{~min}$. The last group was dipped in distilled water and was used as the control samples. After treatment, all samples were drained for $30 \mathrm{~min}$ before storage at room conditions (temperature of $29-31^{\circ} \mathrm{C}$, relative humidity (RH) of $60-70 \%)$ for 5 days. Then, the quality characteristics were analyzed after every day.

\subsection{Fruit Quality Parameters \\ 2.2.1. Weight Loss (WL)}

The same samples were weighed at the beginning of the experiment and at the end of each storage stage. The obtained results were calculated as the percentage loss of initial weight.

\subsubsection{Color Parameters}

The color of the bananas was measured by a CS-10 colorimeter (China) in the CIElab space, and the color parameters $\left(L^{*}, a^{*}\right.$, and $\left.b^{*}\right)$ were recorded. The position selected for color measurement was in the middle of each banana fruit.

\subsubsection{Total Soluble Solids (TSS) Content}

Total soluble solids content ( ${ }^{\circ}$ Brix) was measured using a portable refractometer (ATC, China). 


\subsubsection{Reducing Sugar (RS) Content}

The RS content was determined according to the method reported by Miller [15] with small changes. The 3,5dinitrosalicyclic acid (DNS, yellow color) reacts with the RS in the sample, leading to the formation of 3-amino-5nitrosalicylic acid (red-brown color) which can be quantified by spectrophotometry at a wavelength of $530 \mathrm{~nm}$.

\subsubsection{The Titratable Acidity (TA)}

The TA was determined using the titration method. A $10 \mathrm{~g}$ sample was crushed and mixed with $200 \mathrm{~mL}$ distilled water. Next, the mixture was filtrated using filter paper and filled up to $250 \mathrm{~mL}$ with distilled water. Then, the filtrate, with two drops of phenolphthalein $(0.5 \%$, $\mathrm{w} / \mathrm{v}$ ) as an indicator, was titrated using 0.1 $\mathrm{N} \mathrm{NaOH}$ solution. The obtained results are estimated as grams of malic acid equivalent per $100 \mathrm{~g}$ fresh weight (FW, \%).

\subsubsection{Firmness}

The firmness of the banana peel was measured using the Fruit Texture Analyzer (T.R. Turoni, Italy) with an $8 \mathrm{~mm}$ cylindrical probe, a measuring depth of $1 \mathrm{~mm}$, and a speed of $5 \mathrm{~mm} / \mathrm{s}$. The results were expressed in kilograms (kg).

\subsubsection{Sensory Methods}

Sensory evaluation of the samples was performed using a 9-point hedonic scale from 1 (dislike extremely) to 9 (like extremely), according to the method described by Meilgaard et al. [14]. The 60 non-trained panelists that were chosen evaluated the qualities of the fruit, such as color, odor, taste, texture, and overall acceptability in the last storage period for the best and control sample.

\subsubsection{Microbiological Analysis}

The aerobic plate count, Escherichia coli, Salmonella spp., total yeast and mold count were determined according to ISO 4833-1:2013 [10], ISO 16649-3:2015 [8], TCVN 8342:2010 [21], and ISO 215271:2008 [9], respectively.

\subsection{Data Analysis}

All experiments were performed in triplicates. The obtained data were analyzed using the one-way analysis of variance (ANOVA) method, and specific differences between means were determined by the Fisher's least significant difference (LSD) procedure using Statgraphics Centurion XV software (version 15.1.02, USA) at $p<0.05$. The results were expressed in the form of a mean \pm standard deviation (SD).

\section{Results and Discussions}

\subsection{Effect of Aloe Vera Gels on the WL of Banana Fruit during Storage}

Figure 1 illustrates the WL of bananas coated with various Aloe vera gels. The coated bananas clearly showed lower WL compared to the control samples during the storage time. The $W L$ of samples coated with gel $A, B$, and $C$ ranged from $3.5 \%$ to $20 \%$ while that of the control samples fluctuated from $4.8 \%$ to $23 \%$. The lowest WL was observed in samples coated with gel $\mathrm{A}$ and $\mathrm{C}$. This proved that Aloe vera gel coatings significantly $(p<0.05)$ decrease the WL. For the control samples, they only needed four days of 
storage to reach full maturity (stage 7), while the coated samples needed five days of storage at room temperature. According to some previous studies, Aloe vera can be applied as an alternative to traditional edible coatings used in freshcut fruits [2] and had antioxidant capacity, antioxidant enzyme activities, and reduced the decay in raspberry fruit [7]. Aloe vera gel formed a natural gas barrier that is glossy and transparent and can prolong the shelf life of bananas. However, compared with other storage methods, the rate of WL of coated samples in this study rapidly increased to approximately $20 \%$ after 5 days of storage at $29-31^{\circ} \mathrm{C}$ (RH of $60-70 \%$ ), whereas Cavendish bananas coated with starchcarrageenan matrix blended with sucrose fatty acid esters had a WL of nearly $4.5 \%$ after 14 days of storage at $20^{\circ} \mathrm{C}$ ( $\mathrm{RH}$ of 52\%) [22]. In addition, Dwivany et al. [5] also used carrageenan as an edible film to extend Cavendish banana shelf life, and the obtained $W L$ reached from $28 \%$ to $38 \%$ at room temperature $\left(26^{\circ} \mathrm{C}\right)$ and from $17 \%$ to $23 \%$ at $20^{\circ} \mathrm{C}$ with various carrageenan concentrations after 13 days of storage. These observations can be explained by the fact that the different results were attributed to the various natural sources and storage conditions (edible films, temperatures, $\mathrm{RH}$, etc.), especially storage temperature. Low temperatures caused a decrease in the respiration and transpiration rate of the fruit, thus, resulting in lower water loss [1].

\subsection{Effect of Aloe Vera Gels on the TA of Banana Fruit during Storage}

As seen in Figure 2, there are no significant differences in TA in samples for the same days of storage. However, the TA of the control sample peaked at $4.69 \%$ (malic acid) on day 2, while that of all coated samples had the highest acid values on day 3 (ranging from $4.46 \%$ to $5.58 \%)$ and then slightly decreased. According to Thakur et al. [22], the decrease in TA in banana fruit during storage time is related to a decrease in the organic acid content. The reduction of TA has been ascribed to the conversion of organic acid into sugar and its further utilization in the metabolic processes of the fruit [6]. The increase in the TA values of control or coated samples was only observed during the first two or three days of storage. This was attributed to the strong activity of malate synthase and phosphoenolpyruvate carboxylase. These enzymes have an important role in the formation of malic acid, which is a main organic acid in banana fruit [11]. In general, the trend of TA of sample in this study is in agreement with that observed by Thakur et al. [22] for Cavendish bananas during storage time; however, the obtained TA values are higher than those recorded by these authors (0.15$0.37 \%)$.

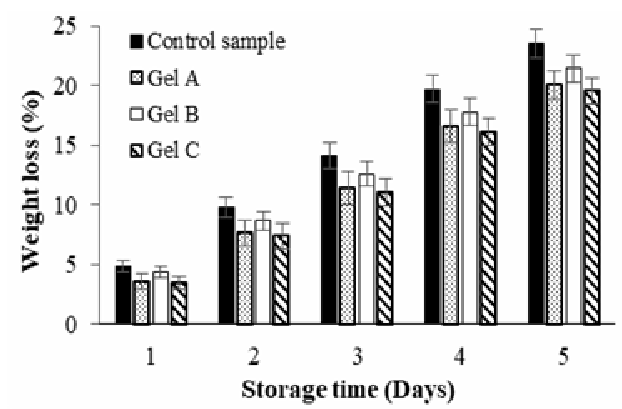

Fig. 1. Effect of Aloe vera gels on the WL of banana 


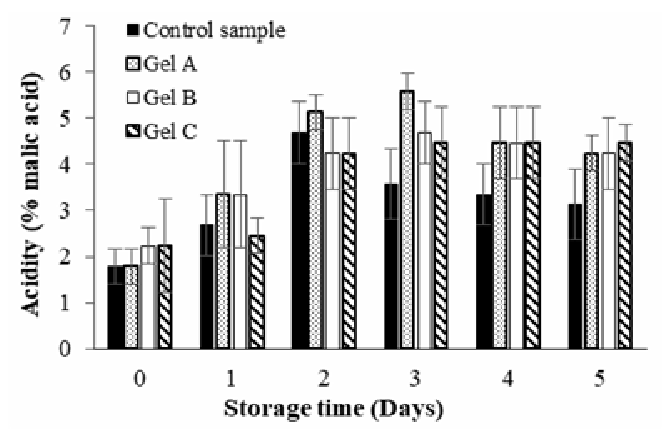

Fig. 2. Effect of Aloe vera gels on the TA of banana

\subsection{Effect of Aloe Vera Gels on the RS and TSS Content of Banana Fruit during Storage}

Figures 3 and 4 show the RS content and the TSS of coated and control samples. In the first two days of storage, the RS content of all samples changed insignificantly, ranging from 0.65 to $1.29 \%$. This revealed that the bananas contained a large amount of starch at this stage. Then, the RS content dramatically increased during the rest storage time, especially the control sample, as it peaked at $18.09 \%$ while the RS content of treated samples fluctuated from 10.05 to $15.48 \%$ on the $5^{\text {th }}$ day. Among all the coated samples, gels $A$ and $B$ showed significantly $(p<0.05)$ lower amounts of RS content compared to that of other samples. In general, the increase in RS content can be explained by the fact that there is a strong enzymatic conversion of starch to sugars to reach full maturity. Essentially, the accumulation of the RS content in coated bananas was found to be less than the control. This finding is also similar to the results reported by Gol and Rao [6], who preserved bananas using various edible coatings, such as chitosan, glycerol, jojoba oil, etc.

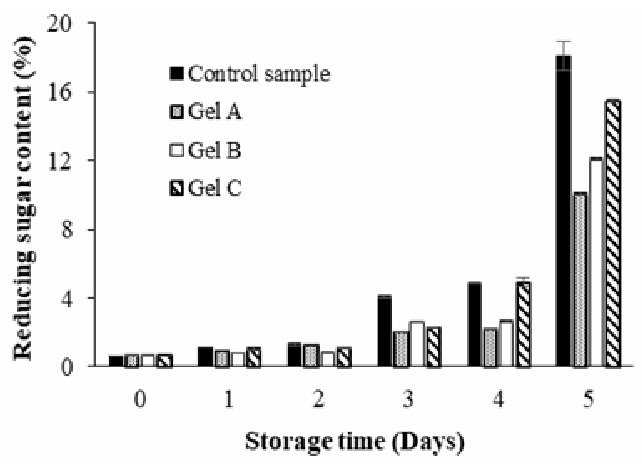

Fig. 3. Effect of Aloe vera gels on the RS content of banana

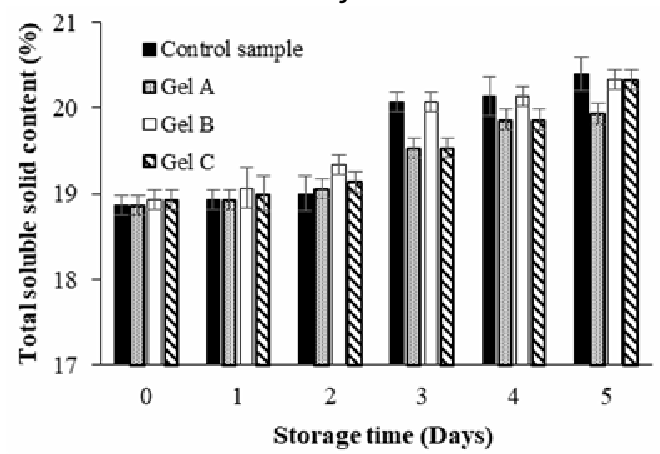

Fig. 4. Effect of Aloe vera gels on the TSS of banana

The TSS content of all samples in the initial period was quite high (approximate 18.9\%). From the $3^{\text {rd }}$ to $5^{\text {th }}$ day, the TSS content slowly increased, ranging from $19.9 \%$ to $20.4 \%$ on the $5^{\text {th }}$ day. In this period, the TSS level of the sample coated by gel $A$ seems to be significantly lower than that of other samples $(p<0.05)$. Compared to other fruits, after storage, the TSS content of bananas surpass that of raspberries (6.7-7.22\%) [7], kiwifruit slices (10-12\%) [2] and Cavendish banana (614\%) [5]. The TSS content in bananas consists of many soluble compounds, such as RS, non RS, organic acid, etc. Besides, according to Thakur et al. [22], the high TSS level in fruit may be attributed to the degradation of starch and dehydration of fruit during storage. In addition, the RS 
was formed by the conversion of starch and non RS to RS through the ripening process of the fruit [6]. In this study, the increased tendency of TSS content is in agreement with those of RS.

\subsection{Effect of Aloe Vera Gels on the Firmness of Banana Fruit during Storage}

Figure 5 shows that the firmness has high values in the two initial days of storage, ranging from 1.38 to $2.27 \mathrm{~kg}$. For the coated samples, their firmness is always higher than those of uncoated samples for the initial period of storage. Then, the banana peel firmness suddenly significantly decreased during the rest scale, ranging from 0.27 to $0.39 \mathrm{~kg}$. The differences of all samples are not significant in this period. This revealed that Aloe vera gels only have a positive effect in the early stages. According to Ullah et al. [23], they pointed out that the lower firmness of the control samples was related to the higher water loss and the weakening of the tissues of the skin of the banana. Besides, the degradation of the cell wall and the transformation of starch in the banana also directly affect the firmness [12]. Protopectin in the peels and pulp of the banana can be transformed into soluble pectin because of the presence of protopectinase in the fruit [19], leading to lower firmness during storage time. The decrease in firmness of the fruit is inevitable, so using edible film coatings, which can extend or enhance the firmness of the fruit, is a very necessary tendency at the present in the fruit preservation process.

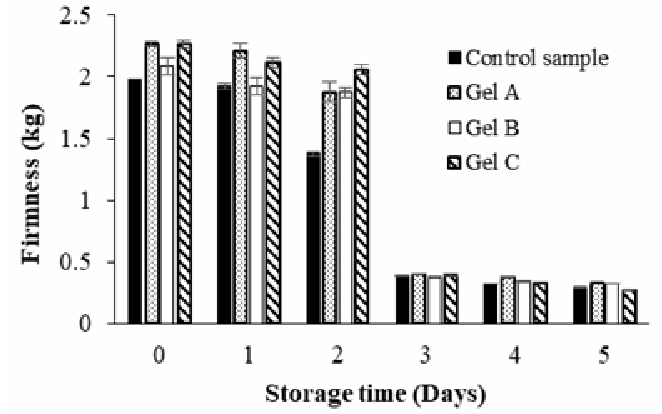

Fig. 5. Effect of Aloe vera gels on the peel firmness

\subsection{Effect of Aloe Vera Gels on the Color Parameters of Banana Fruit during Storage}

Based on the obtained results, the changes in peel color was found to be very different between the control and coated samples $(p<0.05)$ during storage time (Figures 6, 7, and 8). The browning and spotting of the coated samples appear lower than those of control samples. This also caused the $L^{*}$ values of the control sample, which were usually lower than those of the coated samples in the initial and last period of the preservation time. Besides, the peel color with brown spots significantly affected other color parameters, especially the $a^{*}$ values in this study. They slightly rose for 4 days, and then suddenly rapidly decreased at the last day of the storage process. In general, the tendency of $L^{*}$ and $b^{*}$ values of all samples was to steadily increase during storage time except for the control samples. All color parameters of Pisang Awak bananas in this study were lower than those of Berangan bananas recorded by Ding and Ling [4]. This can be attributed to the different banana species and treatment methods. 


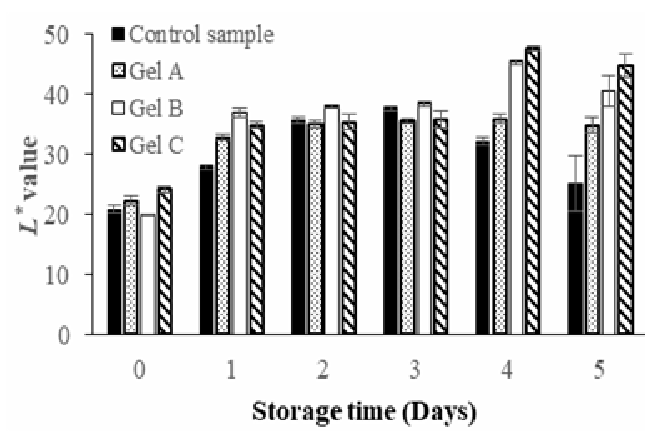

Fig. 6. Effect of Aloe vera gels on the $L^{*}$ values

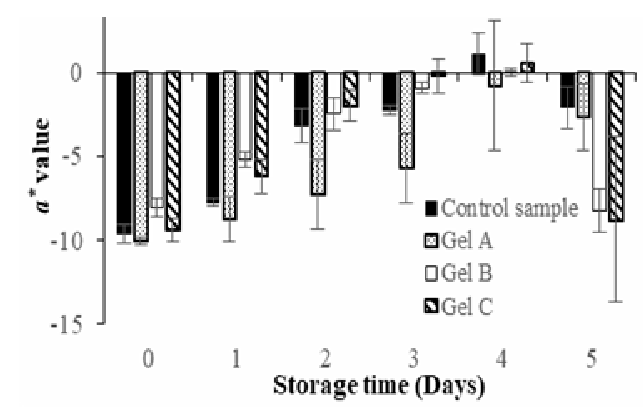

Fig. 7. Effect of Aloe vera gels on the $a^{*}$ values

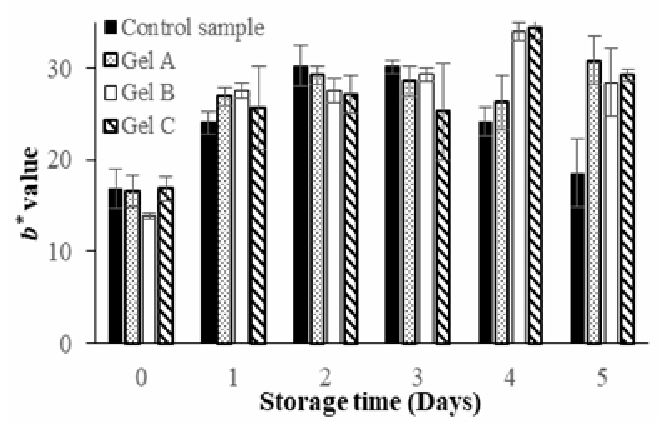

Fig. 8. Effect of Aloe vera gels on the $b^{*}$ values

\subsection{Microbiological Analysis and Sensory Attributes of Banana Fruit}

Based on the recorded observations during storage time, the chemical properties of samples coated with gel B with Aloe vera solution diluted with distilled water (ratio of 1:3, v/v) were in agreement with other coated samples and surpass those of the control. Besides, they have a good appearance by the naked-eye and color parameters $\left(L^{*}, a^{*}\right.$, and $\left.b^{*}\right)$ for 5 days. Consequently, the sample at this concentration was chosen for microbiological analysis and sensory evaluation after 5 days of storage compared to the control sample.

Table 1 shows that E. coli and Salmonella spp. were not detected in both samples. Besides, the total aerobic microbial count and the total yeast and mold count of the coated sample occupied a small proportion. These obtained microbiological parameters completely correspond to national technical regulation of microbiological contaminants in food in Vietnam [18]. According to Benítez et al. [2], Aloe vera gel can inhibit the growth of bacteria, yeast, and mold in fruit. However, the obtained results did not exhibit these clear differences between both samples because the thick peel of the banana can protect the pulp inside to avoid an infection of microorganisms.

Fresh quality is an important factor for consumer satisfaction. In this study, some attributes of the coated banana and control were evaluated, including odor, color, taste, texture, and overall acceptability. From Table 2, it was observed that firmness and color have significant differences $(p<0.05)$ between samples. The scores of two attributes of the sample coated by gel B were higher than those of the control. This proved that Aloe vera gel enhanced quality attributes of bananas, especially firmness and color, while panelists did not perceive a difference in taste and odor of the two samples. The improvement in firmness 
and color leads to a higher overall acceptability of the coated sample. The positive influences of Aloe vera gel in this study are also similar to those reported by Martínez-Romero et al. [13], who also used Aloe vera gel to preserve sweet cherry. It can maintain the quality of the fruit during storage and does not have any detrimental effects on taste, aroma, or flavors.

Microbiological analysis of coated and uncoated products

Table 1

\begin{tabular}{|c|c|c|c|c|}
\hline Samples & $\begin{array}{c}\text { Total aerobic plate } \\
\text { count [Cfu/g] }\end{array}$ & $\begin{array}{c}\text { Escherichia coli } \\
\text { [Cfu/g] }\end{array}$ & $\begin{array}{c}\text { Salmonella spp. } \\
\text { [Cfu/25 g] }\end{array}$ & $\begin{array}{c}\text { Total yeast and } \\
\text { mold count } \\
\text { [Cfu/g] }\end{array}$ \\
\hline Control & $<10$ & - & - & $<10$ \\
\hline Gel B & $<10$ & - & - & $<10$ \\
\hline
\end{tabular}

Regarding to the test method, the results were expressed as less than $10 \mathrm{Cfu} / \mathrm{g}$ when the dish contains no colony

"_": Not detected

Sensory evaluation of coated and uncoated products

Table 2

\begin{tabular}{|c|c|c|c|c|c|}
\hline Sample & Firmness & Color & Taste & Odor & Overall acceptability \\
\hline Control & $5.8 \pm 1.7^{\mathrm{a}}$ & $5.0 \pm 1.7^{\mathrm{a}}$ & $6.8 \pm 1.7^{\mathrm{a}}$ & $6.6 \pm 1.6^{\mathrm{a}}$ & $6.7 \pm 1.6^{\mathrm{a}}$ \\
\hline Gel B & $6.6 \pm 1.4^{\mathrm{b}}$ & $6.1 \pm 1.6^{\mathrm{b}}$ & $7.1 \pm 1.8^{\mathrm{a}}$ & $6.2 \pm 1.7^{\mathrm{a}}$ & $7.3 \pm 1.3^{\mathrm{b}}$ \\
\hline
\end{tabular}

Different superscript lower-case letters in the same column denote significant differences $(p<0.05)$.

\section{Conclusions}

In general, to our knowledge, this is the first time that Aloe vera gel was used as an edible coating in bananas. It can maintain the quality of Pisang Awak bananas during storage. This gel can enhance some quality properties compared to the control. Besides, an optimal gel concentration (gel $B)$ has positive influences in retarding the ripening process. This treatment decreased the WL and TA losses, delayed softening and color changes, and improved banana quality. This demonstrated that Aloe vera gel can be widely applied in post-harvest technology in the future.

\section{Acknowledgements}

This research was performed at the Institute of Biotechnology and Food Technology, Industrial University of Ho Chi Minh City (Vietnam). The author would like to thank Nguyen Thi Bich Hoa, Nguyen Tran My Tien, and Hoang Thi Thuy Trang for their helpful advices on various technical issues examined in this paper.

\section{References}

1. Ahmad S., Thompson A.K., Hafiz I.A. et al., 2001. Effect of temperature on the ripening and quality of banana fruit. In: International Journal of 
Agriculture and Biology, vol. 3, pp. 224-227.

2. Benítez S., Achaerandio I., Pujola M. et al., 2015. Aloe vera as an alternative to traditional edible coatings used in fresh cut fruits: $A$ case of study with kiwifruit slices. In: LWT - Food Science and Technology, vol. 61(1), pp. 184-193. doi: 10.1016/j.Iwt.2014.11.036.

3. Boudreau M.D., Beland F.A., 2006. An evaluation of the biological and toxicological properties of Aloe barbadensis (Miller), Aloe vera. In: Journal of Environmental Science and Health, Part C - Environmental Carcinogenesis and Ecotoxicology Reviews, vol. 24(1), pp. 103-154. doi: 10.1080/10590500600614303.

4. Ding P., Ling Y.S., 2014. Browning assessment methods and polyphenol oxidase in UV-C irradiated Berangan banana fruit. In: International Food Research Journal, vol. 21(4), pp. 1667-1674.

5. Dwivany F.M., Aprilyandi A.N., Suendo V. et al., 2020. Carrageenan edible coating application prolongs Cavendish banana shelf life. In: International Journal of Food Science, vol. 2020, ID 8861610. doi: $10.1155 / 2020 / 8861610$.

6. Gol N.B., Rao T.V.R., 2011. Banana fruit ripening as influenced by edible coatings. In: International Journal of Fruit Science, vol. 11(2), pp. 119-135. doi: 10.1080/15538362.2011.578512.

7. Hassanpour H., 2015. Effect of Aloe vera gel coating on antioxidant capacity, antioxidan enzyme activities and decay in raspberry fruit. In: LWT Food Science and Technology, vol. 60(1), pp.495-501. doi: 10.1016/j.Iwt.2014.07.049.
8. ISO 16649-3:2015. Microbiology of food and animal feeding stuffs Horizontal method for the enumeration of beta-glucuronidasepositive Escherichia coli - Part 1: Colony count technique at 44 degrees $C$ using membranes and 5-bromo-4chloro-3-indolyl beta-D-glucuronide.

9. ISO 21527-1:2008. Microbiology of food and animal feeding stuffs Horizontal method for the enumeration of yeasts and moulds Part 2: Colony count technique in products with water activity less than or equal to 0.95 .

10.ISO 4833-1:2013. Microbiology of the food chain - Horizontal method for the enumeration of microorganisms. Part 1: Colony count at 30 degrees $C$ by the pour plate technique.

11.John P., Marchal J., 1995. Ripening and biochemistry of the fruit. In: Bananas and Plantains. Gowen S. (Ed.). Springer Science, Dordrecht, Netherlands, pp. 434-467.

12.Juncai $H .$, Yaohua $H$. , Lixia $H$. et al., 2015. Classification of ripening stages of bananas based on support vector machine. In: International Journal of Agricultural and Biological Engineering, vol. 8(6), pp. 99-103. doi: 10.3965/j.ijabe.20150806.1275.

13. Martínez-Romero D., Alburquerque N., Valverde J. et al., 2006. Postharvest sweet cherry quality and safety maintenance by Aloe vera treatment: a new edible coating. In: Postharvest Biology and Technology, vol. 39(1), pp. 93-100. doi: 10.1016/j.postharvbio.2005.09.006.

14. Meilgaard M.C., Civille G.V., Carr B.T., 2007. Sensory evaluation techniques. CRC Press, New York, USA. 
15. Miller G., 1959. Use of dinitrosalicylic acid reagent for determination of reducing sugar. In: Analytical Chemistry, vol. 31(3), pp. 426-428. doi: 10.1021/ac60147a030.

16.Park H.J., 1999. Development of advanced edible coatings for fruits. In: Trends in Food Science \& Technology, vol. 10(8), pp. 254-260. doi: 10.1016/S0924-2244(00)00003-0.

17.Petersen K., Nielsen P.V., Lawther M. et al., 1999. Potential of biobased materials for food packaging. In: Trends in Food Science and Technology, vol. 10(2), pp. 52-68. doi: 10.1016/S0924-2244(99)00019-9.

18.QCVN 8-3:2012. National technical regulation of microbiological contaminants in food in Vietnam. (National technical regulation), Vietnam.

19.Sakai T., Ozaki Y., 1988. Protopectin solubilizing enzyme that does not catalyze the degradation of polygalacturonic acid. In: Agricultural and Biological Chemistry, vol. 53(4), pp. 1091-1093. doi: 10.1080/00021369.1988.10868782.
20.Sidhu J.S., Zafar T.A., 2018. Bioactive compounds in banana fruits and their health benefis. In: Food Quality and Safety, vol. 2(4), pp. 183-188. doi: $10.1093 /$ fqsafe/fyy019.

21.TCVN 8342:2010. Fish and fishery products-Detection of Salmonella using Polymerase Chain Reaction (PCR) technique. (Vietnam Standards)

22. Thakur R., Pristijono P., Bowyer M. et al., 2019. A starch edible surface coating delays banana fruit ripening. In: LWT - Food Science and Technology, vol. 100, pp. 341-347. doi: 10.1016/j.Iwt.2018.10.055.

23.Ullah H., Ahmad S., Anwar R. et al., 2006. Effect of high humidity and water on storage life and quality of bananas. In: International Journal of Agriculture and Biology, vol. 8(6), pp. 828-831.

24.Veroustraete F., 2016. Can ethylene, a simple gaseous hydrocarbon, be considered as a plant hormone or as an ozone antagonist? In: Photobiology and Plant Physiology, vol. 2, pp. 4-11. 